\title{
LEARNING TO BECOME A TEAM PLAYER. SITUATED LEARNING IN PARALYMPIC SLEDGE HOCKEY
}

\author{
Espen Hegde, Øyvind F. Standal
}

Norwegian School of Sport Sciences, Norway

Over the past three decades, the academic interest in the field of physical activity and disability has expanded significantly (Thomas, \& Smith, 2009). One aspect that has received less attention is the internal dynamics of sport teams of disabled athletes. The purpose of this study is to investigate social learning processes that take place in Paralympic team sport contexts. Using a qualitative approach within the framework of situated learning (Lave, \& Wenger, 1991), a group of sledge hockey players was interviewed individually regarding their personal initiation and development within the team. Two primary themes emerged from the data analysis; the internal structure of the community of practice and achievement of legitimate peripheral participation on-ice and off-ice. The results offer preliminary evidence that newcomers undergo a specific period known as the "rookie period" in order to become part of the team. The completion of this period appears as a necessity if further learning shall take place. Further research is needed to explore whether these findings are transferable to other sports contexts and whether participants' identities are affected by their participation.

Keywords: Paralympic sport; situated learning; sledge hockey.

\section{INTRODUCTION}

Despite being a relatively new phenomenon, the field of physical activity and disability has received increased academic interest over the past three decades (Thomas \& Smith, 2009). The interest is mainly aimed at concepts like disability sport development in local authorities; challenges with disabilities in relation to physical education and school systems; mainstreaming disability sport; and elite disability sport and the Paralympic Games (Thomas \& Smith, 2009).

Bruner and colleagues (2008) claim that the desire to understand, how different athletic career transitions affect athletes, has increased during the past four decades. Through performing 120 interviews with American elite athletes, Bloom (1985) was one of the first to provide a description of how athletes experience the transition into elite sports. The findings indicated that athletes undergo a developing phase, when entering elite sports. As stated in Bloom's (1985) research, this includes, among other things, an adoption of a set of behaviors and beliefs, which are often perceived by athletes as a struggle. In addition, the results pointed to a clear tendency of elite athletes to be exposed to both social and physical challenges. Personal and familiar sacrifices were made, while at the same time the intensity and expectations regarding the development of performance skills increased. Bruner and colleagues (2008) provided a notable contribution by investigating the transition of rookie ice hockey players (Major Junior "A" teams) into elite sport. The study consisted of two focus group interviews with four players in each group $(\mathrm{N}=8$, mean age $=$ 17, 12 years) from two Major Junior ' $A$ ' Ontario Hockey League (OHL) teams. The results were divided into on-ice and off-ice related issues. More specifically, the study suggested numerous themes in relation to entering an elite sport context (e.g., experiencing a reduction in self confidence; a shift in the social support; the relationship between athletes). Bruner and colleagues (2008) were surprised with the results by nonappearance of a phenomenon called "hazing". That is a process of socialization, where a rookie player become initiated into the elite 
level of sport (O'Hara, 2000; Robinson, 1998).

In connection with social groups, apprenticeship, participation and learning, Lave and Wenger (1991) introduced the theory of situated learning. The theory seeks to understand how learning emerges from participation in social contexts. While situated learning initially focuses on learning in general, it was not until the past 10-15 years that sport researchers started considering sport teams with this theoretical framework, thus started treating them as athletic communities of practice (Ronglan, 2009). In addition, Ronglan (2009) highlighted the importance of investigating these communities in order to refine them as learning arenas. In particular, this enables an increased understanding of the on-going learning processes in such communities.

Even though existing research (Bloom, 1985; Bruner et.al., 2008; Ronglan, 2009) has provided a considerable contribution in the understanding of athletic communities of practice and its effects of players' participation in teams, little knowledge has been provided about the internal dynamics of specific Paralympic sports. Furthermore, less attention has been drawn to how disabled athletes learn and develop skills through participation in elite athletic communities of practice. Understanding processes of learning and development within elite sport team contexts can be of importance both for coaching practices and the education of future coaches.

The purpose of this study is to investigate social learning processes that take place in Paralympic team sport contexts. More specifically, we have analyzed the internal dynamics of the National Sledge Hockey Team in Norway, using the following research question: what kind of social learning processes take place within Norwegian Sledge Hockey Team? Describing this phenomenon via the implementation of the qualitative approach and the framework of situated learning (Lave \& Wenger, 1991), the study intends to contribute to understand athletic communities of practice in general; and in relation to physical activity and disability in particular.

\section{Conceptual Framework}

The theory of situated learning provides an understanding of how learning takes place and how meaning emerges through participation within social practices (Lave \& Wenger, 1991).

Situated learning is based on anthropological studies of apprenticeship and understands learning as "an integral and inseparable aspect of social practice" (Lave \& Wenger, 1991, p.31). The term "situated" refers to apprehension of an activity as connected to the life and biography of an individual, while at the same time located within a specific culture (Ronglan, 2009). Moreover, learning is viewed as a process based on participation and involvement in social contexts (Ronglan, 2009; Standal, \& Jespersen, 2008). This indicates that learning is primarily understood within a participation framework, rather than something explained solely by processes taking place in individuals' minds (Hanks, 1991).

By using terms as communities of practice and legitimate peripheral participation, the theory of situated learning provides new insight and understanding of the social foundation and dynamics of learning (Ronglan, 2009). Ronglan (2009) argues that the theory is well-suited for reflections connected to athletic communities of practice. In addition, it can help to develop and improve learning arenas.

Wenger and co-workers (2002) define a community of practice as "a group of people who share a concern, a set of problems, or a passion and who deepen their knowledge and expertise in this area by interacting on an ongoing basis" (Wenger et al., 2002, p.4). According to (Wenger, 1998), a community of practice consists of three constituting dimensions;

Mutual Engagement: constitutes the basis for every practice and refers to a variety of skills, which is brought into the community by 
participants. Wenger (1998) emphasizes that the most productive communities of practice are characterized by a high degree of heterogeneity among its members. On the foundation of mutual engagement, various relationships between participants may occur, including confidentiality, competitions, challenges and conflicts.

Joint Enterprise: A community of practice is not necessarily characterized by peace and harmony. Wenger (1998) claims that conflicts may have positive effects on the community as they create dynamism and hereby prevent practices from becoming static and conservative. Despite potential conflicts, participants will always be part of performances of the particular community. They must therefore establish a common negotiated practice that makes them able to function as a joint enterprise.

Shared Repertoire: Wenger (1998) uses the concept of shared repertoire to refer to a set of routines, terms, artifacts, symbols and actions inside a community of practice. In addition, the concept covers knowledge and skills that have been developed by participants over time. In this way, the concept reflects a history of mutual engagement and joint enterprise while at the same time represents the foundation for future practice development (Jensen, 2006; Wenger, 1998). The shared repertoire achieves its relevance in relation to a community of practice, because this is where it emerges, develops and is used to negotiate meaning (Wenger, 1998).

The term legitimate peripheral participation is used to emphasize the process where newcomers become part of an established community of practice, and where relations between new and experienced members are formed (Lave \& Wenger, 1991;

Wenger, 1998). By achie-ving legitimate peripheral participation, the newcomer receives access to knowledge that exists in the community (Bakke \& Tønnesen, 2007). Moreover, the newcomer will be able to acquire skills and attributes by observing, imitating and interacting with experienced members (Nielsen \& Kvale, 1999). According to Ronglan (2009), in the context of athletic communities of practice, experienced members function as masters and hereby essential sources to knowledge and learning. Participation creates foundation for advancement within the community, where the newcomer can in time move from a peripheral to central position. This process is connected with the understanding of how meaning occurs, as stated by Lave and Wenger; "the meaning of learning is configured through the process of becoming a full participant in a sociocultural practice" (Lave \& Wenger, 1991, p.29).

\section{METHOD}

The purpose of this study aims to gather, interpret and analyze data collected from players in the Norwegian Sledge Hockey Team in order to better understand the social learning processes that take place within this team. The qualitative research interview seeks to understand the world from the interviewee's point of view and is therefore considered a suitable method, because it is the subjective point of view that matters the most in qualitative studies (Kvale \& Brinkmann, 2009).

\section{Participants}

The primary researcher preliminary approached the National sledge hockey team, which represents Norway in international competitions to explore, if anyone would be interested in participating in a research study. Five players were identified as ideal participants based on maximum variation (Denzin \& Lincoln, 1994). These were five males ranging from 22 to 31 (age $M=25.6 \mathrm{yrs}$; $S D=3.1$ yrs) years. They had spent a various amount of time in the team ranging from 2 to 9 years (time $M=6.3 \mathrm{yrs} ; S D=2.4 \mathrm{yrs}$ ) Three have had spinal cord injuries, one has had a neurological disease and one has become an amputee. Two of the participants were born with their condition, while the other three have 
acquired their disabilities later in life. The remaining information regarding participants will be retained in order to secure their anonymity. In addition, the participants have been given fictive names. This step was necessary due to the small size of the Norwegian sledge hockey community. In the following these players are referred to with the fictional names: Martin, Alex, Logan, Tim, and Kyle. In the results, quotations from the players will be presented.

The reader should be aware of the dual role of the primary researcher. Owing to the fact that he is an assistant coach of the Norwegian Sledge Hockey Team, it is clear that he has had pre-existing history with the participants of the study. This also implies that he has known the participants and community in general before the study was effectuated. The pre-existing knowledge of the community could be considered as an area of tension, where this insight might affect the understanding of the study's results, which can be both beneficial and detrimental to the particular findings. Moreover, the dual role of the researcher involves ethical challenges in the sense that participants might feel obligated to the researcher or influenced by the power relationships. It was therefore clarified that no statements would have any effect on the relationship between the coach and particular athletes.

\section{Interviews}

A study aimed at examining individual lived experiences typically rely on a semistructured, in- depth interview strategy (Marshall \& Rossman, 1999). The semistructured interview takes advantage of the pragmatic, interpretive and grounded nature of qualitative research and was therefore selected as a suitable method (Marshall \& Rossman, 1999). The interviews were loosely structured around an interview guide, which consisted of a combination of open-ended questions, subquestions and leading questions. This was to ensure that the interviewer would be able to gather as much concrete and correct information from the participants as possible. At the same time participants were given space and privacy to answer in a way they felt comfortable.

All five interviews were conducted and digitally recorded in quiet surroundings at a training facility in Oslo. The interviews lasted from 75 to 120 minutes. The interviews began with an introduction to the project, clarification of the purpose of the study, as well as the ethical considerations involved. Participants were informed that they could withdraw from the interview at any time without any further explanation.

All interviews were transcribed by the first author right after the completion of each interview or within the next day. To ensure accuracy, all transcripts were checked against the tape from the interview before moving on to further analysis. This research was reviewed and approved by the Norwegian committee responsible for the ethical issues - the Data Inspectorate of Norway. In addition, athletes gave their informed consent to participate in the study.

\section{Data Analysis}

Interpretation requires explanation of findings, attachment of significance to particular results and placement of patterns into an analytic framework (Patton, 2002). In this study, the analytical procedure followed the six phases of Marshall and Rossman (1999). First, the summaries of the interview transcripts were organized in accordance with the interview guide. They contained all defined key phrases and terms. Second, a number of underlying themes were identified. Throughout this process, four analyst-constructed typologies were established and all categories and themes with their accompanying data were organized in a matrix. The third phase was to color code the presence or non-occurrence of a phenomenon within the matrix. The following phase was to test the emergent understandings. After this, the search for alternative explanations took place. Based on the color coding, the disconfirming statements appeared 
as well-arranged and easier to interpret and analyze. Before moving on to the final phase (producing the written report), the data analysis was discussed with the second author who had read through the transcripts and commented on the analysis. Being the supervising researcher, he was given access to the data material and was hereby included in the analytical procedures.

\section{Trustworthiness}

The trustworthiness of a study should be planed for and paid attention to during the entire inquiry (Lincoln \& Guba, 1985). Qualitative research can, through establishing credibility, transferability, dependability and confirmability, appear as quite persuasive (Lincoln \& Guba, 1985). First of all, a number of safeguard-precautions were formulated (e.g. building trust and rapport with the participants and making sure to be aware of possible distortions due to the researcher's dual role). That was necessary considering the potential distortions arising from the dual role of the researcher. The researcher took into consideration the role-status differentials and pre-existing knowledge and thus aimed at providing a satisfactory judgment of trustworthiness (Guba, 1978; Lincoln \& Guba, 1985). The researcher's dual role resulted in an increased probability for credible findings, as he knew the participants well (Lincoln \& Guba, 1985). Another step in the data analysis was to look for dis-confirming evidence (Brantlinger, Jimenez, Klinger, Pugach, \& Richardson, 2005) where the researchers looked for statements that contradicted the initial analysis.

Member checking was conducted using "the naïve researcher" technique, which included follow-up questions for clarifycation. Furthermore, all participants were provided with an oral summary at the end of each interview (Lincoln \& Guba, 1985). Based on the pre-existing knowledge of the researcher, an interview guide was designed in order to provide participants with the opportunity to speak freely without time constraints. The process of forming the interview guide included consultations with the supervising researcher. This, in connection with follow-up questions, created the basis for complex descriptions leading to transferability (Lincoln \& Guba, 1985). The researcher focused on making the process of the inquiry as transparent as possible by an audit trail creation as recommended by other researchers (Lincoln \& Guba, 1985; Kvale \& Brinkmann, 2009). Therefore, field notes were created and the analytical framework of Marshall and Rossman (1999) was followed. Confirmability was enhanced by providing access to the interview transcripts to the project supervisor in order to examine the research product and coordination between data material, analytical process, findings and recommendations (Lincoln \& Guba, 1985).

\section{RESULTS}

The data analysis revealed two main dimensions within the Norwegian Sledge Hockey Team; the on-ice and off-ice arena. The on-ice arena is where the members develop performance skills, while the off-ice arena is where they establish their individual roles and strive for social acceptance. These arenas embrace every aspect of the community's practice and mutually affect each other, while at the same time are clearly separated. As stated by Logan: "If you're in the locker room you're one person, and when you're on the ice you're another person". The mutual influence is expressed by Martin: "The faster you get accepted off-ice, the faster you'll be accepted on-ice". The findings will be presented in two distinct groups;

Entering the team: According to the data analysis, the purpose of the rookie treatment is that new members are ensured inclusion and learning of necessary skills. The newcomers are bound to undergo the treatment in order to become accepted.

The process of internal advancement: In order to understand the process of internal advancement it is beneficial to understand the 
formal and informal roles within the particular team. The informal roles are associated with the process of establishing a personal basis for participation. The formal roles are more obvious since they are given to central members and include great responsibility both on and off the ice. These results will be elaborated below.

\section{Entering the Team}

The community separates between new and established members, as expressed by Martin: "It should be a clear division between established and rookies. The rookies gets the rookie-tasks and the rest of us... we're established". Being "the rookie" appears to be a well-known phenomenon: "When you're the rookie, you are treated badly. That's the way it is. You're called names like rookie, poorly skilled, and this and that. You basically get the treatment" (Tim). Logan described the rookie like this:

It's you that is being joked around with, you must pick up the pucks, you have the responsibility for the locker room, you're sort of the newcomer, you are the last guy in, you're the newest on the national team.

All participants reported that they were welcomed by the established members before being exposed to the rookie treatment. Regardless of previous achievements, the newcomer is bound to start at the bottom of the hierarchy. This is expressed by Kyle: "You really start from scratch in a way and... of course it stinks [laughs] I thought it stunk too (...) I was subconsciously aware that I was ranked at the very bottom". As a newcomer, it appears important to participate off-ice. The community seems aware of the fact that it takes time to develop the skills necessary to perform on-ice. This is expressed by Logan: "Obviously, that's the first task you'll get. If you are unable to, if you're not good enough on the ice (...), then it's the off-ice qualities that count". Even though the community can appear quite harsh, there are situations where the established members adjust to support the rookie. In fact, the intensity of the treatment might both increase and decrease depending on the rookie's response. If the rookie responds with insecurity, the intensity of the treatment will decrease to a comfortable level. As described by Tim: "We'll push the limits all the way, but when the person concerned says; 'That's enough!' Or if we can tell that he is offended or hurt, we'll stop instantly, and those who were involved will talk to him". On the other hand, if the rookie refuses to carry out his responsibilities, the treatment will escalate until he gives in or withdraws from the community, as described by Kyle:

You'll always hear it if you refuse to do things. You'll always hear it from someone, well, we usually take it slow at first like; 'Hey, listen up, this is how it is!' And help you to get a foot inside, and explain for the person or persons too, but if you still won't listen it might, [laughs]... escalate.

Alex provides an illustrative example of this phenomenon: We had one guy at the team a while ago, who completely refused to be the rookie. He wouldn't clean the locker room and things like that - it wasn't his job, he said, and the other members didn't appreciate that.

When asked what eventually happened to him, Alex replied: "He had been active in [an individual sport] in the past and returned to doing that". The aspect of learning appears to be an important feature throughout the rookie period. The data analysis indicated that the rookie treatment aims at ensuring that inclusion and learning of necessary skills take place, as exemplified by Tim:

They (the established members) took the time necessary to explain things, practice drills at the club and national team, that all the equipment is supposed to be organized the same way, and I, of course, was the rookie and had to be the last one out of the locker room and clean it up, making sure that everything was in order and things like that right, before the upcoming training the next day.

Moreover, Tim describes, how he obtained both on-ice and off-ice related skills: "The most established taught me the tactics including different strategies and (...) those 
with less routine, those who had played for five-six years, taught me the techniques". In addition, as highlighted by Martin, the process of becoming a sledge hockey player consists of more than acquiring practical skills:

My willingness to work out was on a much lower level back then compared to what it is now. Back then the focus was more on women, partying and other things. So that was not a contributing factor on improving my level of acceptance in the group (...) it might have helped... with better attitudes at the time... but then again, I didn't know what it meant either. (...) You must learn what it means to be a professional athlete too.

\section{The Process of Internal Advancement}

In order to understand the process of internal advancement, it is advantageous to have the insight into both formal and informal roles. The informal roles are associated with the process of establishing a personal basis for participation. Three kinds of informal roles appeared in the data; the calm and quiet, the clowns and the dominant. These roles are dynamic, socially constructed and include different responsibilities in connection with maintaining the internal dynamics of the community; the calm and quiet provides stability and takes care of new members; the clowns regulate the tension by creating laughter and motivation; the dominant provides initiative and performance orientation. All members have some amount of each role within themselves, as expressed by Logan: "Everyone is a bit clown, everyone has a bit of everything, but there are players who are completely calm in the locker-room, who don't do anything, that are completely raw on ice". As the quote suggests, the informal roles may change between the arenas. When being on ice, members who are calm and quiet office may become dominant, while at the same time, those who are dominant off-ice may adjust to a calmer level when participating onice. This is supported by Kyle: "It's something completely different, when you get your helmet on and sit on the ice, then we're all on the same level". In addition, all roles are of unique importance, as described by Logan in connection with his responsibilities as a clown:

My responsibilities are more like the locker room, the shouting, motivating the guys, you're supposed to bring the guys up when they're feeling down (...) So that is, that is part of being the clown too, not just, you're not just fooling around all the time. Furthermore, Kyle emphasized the importance of the calm and quiet role: "It's important with the calm and quiet ones too, so there's... it creates calmness so that things don't get all crazy. So, it's important with a mix of different personalities.

The formal roles include great responsibility both on and off ice and are therefore perceived as central participation by the players. Furthermore, in order to advance internally and obtain formal roles, players must show a high level performance both on-ice and off-ice over time, as expressed by Tim:

You must be a contributing team player in the locker room, demonstrate that you really want this! When you enter the ice, it should be the exact same way (...) You won't gain my respect, if you perform in one of the two. You must do it in both.

One of the most obvious examples is the supervisory body known as The Captains Group. This group represents the core of the community and is responsible for the continuation and maintenance of practices, traditions and routines, as explained by Martin:

It's those, who the head coach consults with, when there are questions regarding... well, both on and off the ice really. It usually is the captain, two assistant captains and potentially one or two more that constitute The Captains Group. Together with the head coach they discuss tactics, where different members play, which players should be invited to try out for the team and so on.

Another example is the trustee group. Two established members are elected, the main trustee or the vice-trustee. They are responsible for the well-being of the other members through offering social support and understanding. Moreover, they are responsible 
for taking care of the rookies and organizing social events when the team is on tour. As the current vice-trustee, Kyle describes the role like this:

It means that the other members of the team can come to me and talk, if there's anything (...) I talk a lot with the new guys, the newcomers, those who are on recruitment and things like that. I have close contact with some of them, both in everyday life and at gatherings.

Another aspect of internal advancement is associated with the retirement of veteran members. When this takes place, the remaining members must fill the void left behind in order to ensure the continuance of the community; "The veteran player that taught me, he has retired now unfortunately, but then I'll carry the knowledge further on, right. The things he taught me, I'll transfer to the next generation, and that's how it goes" (Tim). With one exception, all participants reported that the retirement of veteran members would lead to internal advancement in both arenas. This internal advancement will automatically increase personal responsibility in both arenas at the same time, as the participants will establish a stronger status and move closer to full participation:

It's connected to the last couple of years' retirement of some established members, and that I have gained more experience, and this way I suddenly became the established. And... well, from there on I had to take more responsibility and show better attitudes and... contribute more, quite simply, both on and off ice (Martin).

\section{DISCUSSION}

The results of this study are related to the internal practices of an athletic community of practice. Interviews with elite sledge hockey players showed that new players initiated into the team are able to progress through different stages of formal and informal participation. The results will be discussed in relation to the theory of situated learning (Lave \& Wenger, 1991; Wenger, 1998), which served as a framework for the study.

It seems relevant to discuss the initiation to the Norwegian Sledge Hockey Team through the concept of legitimate peripheral participation. This concept was developed in order to capture newcomers' opportunities for learning specifically in communities, where newcomers are not expected or able to fully participate at the time of their entry (Lave \& Wenger, 1991). The results of this study indicate that one of the biggest challenges related to recruitment and development of new players is the distribution of legitimacy, e.g. that newcomers are given a certain sense of belonging. It appears important for newcomers to get involved and be able to participate in activities in the community of practice, while trying to build relationships with established members. On the other hand, the more established members seem to be responsible for the allocation of newcomers with legitimacy. In particular, this takes place through the so-called rookie-treatment that the participants in this study all referred to.

Whereas in able-bodied sport new players may present an immediate threat to established players' positions as stars or first-liners, the situation is different in the Paralympic context investigated here, because the recruitment situation is totally different. As the results indicated, the rookies are usually not in a position to make an immediate contribution to the team's performance, and they are therefore more like apprentices. Thus, experienced players are all concerned with the lack of recruitment, and the rookie period in this context can be seen to have a more positive and creative function than merely being a jock phenomenon. This underscores the importance of understanding the learning processes that are described in this paper.

Although, newcomers will be considered "rookies" when entering the community, the results indicate that this will include allocation of legitimacy. Moreover, newcomers must 
undergo "the rookie treatment" in order to maintain and increase legitimacy. However, if insufficient legitimacy is allocated, learning appears challenging. In such cases, newcomers will be deprived of their access to valuable learning resources present in the community (Wenger, 1998). The example of the rookie who came from an individual sport and refused to do the rookie tasks (see above) illustrates this.

Thus, the rookie treatment can be understood as a formative process where the newcomers are shaped to fit the joint enterprise of the community. The established members seem to form the rookies through active usage of shared repertoire, which includes exposing rookies for certain tasks (e.g. picking up the pucks and cleaning the locker room) and local jargon (e.g. pranks and humor). This exposure may result in essential learning both on-ice and off-ice. Moreover, these tasks seem to create contexts where a rookie can participate and demonstrate his potential within the team. In some cases, this treatment can appear similar to the phenomena of hazing. If the rookie does not understand or is incapable of relating to the local jargon and other tasks, he may also experience difficulties with participation in general. Only when newcomers are assimilated to the community, will they have the opportunity to participate in local practices both on-ice and off-ice, gain legitimacy and thereby pursue further learning and development.

According to the situated learning theory, knowledge is distributed within the particular community. This means that knowledge is not only individuals' property. It is present within members' relationships and shared among them. Our results indicate that the team members acknowledge the idea that "the rookie is here to learn". Thus, being a rookie can be considered a favorable position, because knowledge and learning is presented by and through the established members. When the rookie gets to the on-ice arena, he learns and develops sufficiently by observing, imitating and interacting with established members and internal practices.

In addition, off-ice learning appears to be the most important learning arena during the rookie period. We argue that there are three possible reasons for this. First, based on lack of experience, the rookie will most likely be unable to contribute to on-ice practices. The community is aware that it often takes time to develop on-ice skills at a contributing level. Second, the rookie might find it easier to adapt and contribute during off-ice practices. The results indicate that players who have previous experience from team sports face a smoother initiation compared to those who have participated in individual sports or no sport at all. Third, the most important issue for the established members seems to be convinced that the rookie will be able to adapt to and participate in the joint enterprise and shared repertoire of the team. This way the established members can rest assured that the rookie will be able to participate alongside other members and perhaps, in time, move towards a central role in the community.

The off-ice arena is where the members spend most of their time together and the foundation for the on-ice arena is created. If rookies' participation in the off-ice arena is unstable, chances are that on-ice performance will suffer. In other words: If a rookie demonstrates behaviors and attitudes that established players see as opposing or bad, he might be considered as unable to participate in internal practices of the team. Moreover, the results indicate that this kind of behavior will result in loss of legitimacy, and if no changes are made, the treatment will expand until the rookie either subjects to or leaves the community. An example of this was mentioned above with the former athlete from an individual sport, who objected to the rookie treatment. This process of regulation seems to be important to the community because it may provide continuation of the communities' practice. This does not necessarily imply that all participants must think and act alike, but as 
stated by Wenger (1998), the identities that are created through belonging tends to lead to joint response, action and emphasis on different values. Furthermore, in order to produce a collective product, it is essential that the participants' understanding of practice is as similar as possible (Wenger, 1998). This might contribute to understand the demonstrative behavior of the established members. In addition, the results suggest that through gaining legitimacy and participate over time, the rookie will be able to gradually emerge within the internal practices and hereby create a starting point for internal advancement. Finally, the results state that the most intense process of learning takes place during the rookie period. It should be emphasized that the off-ice arena stands out as the most significant arena of participation during the initiation.

Apprenticeships emerge as an important form of learning in the world of sports (Jespersen, 1999). It is further emphasized by Wenger (1998) that the most productive communities of practice are characterized by high degree of heterogeneity among its members. We can imagine that a sports team include several "master - apprentice" relations, which in this context exist within the relationship between newcomers and established members with extensive experience in internal practices (Ronglan, 2009). The generational encounters make the local learning resources available for participants, as stated by Tim in connection with his development of skills both on-ice and off-ice. Experienced members serve not only as a source of information in relation to internal practices; they also represent community's history through themselves. They appear as living examples of what is achievable, expected and desired through prolonged participation. The exposure to these individual trajectories may provide newcomers with a significant factor of learning (Wenger, 1998).

Different generations bring different perspectives into internal practices. This is associated with an emphasis on either conservative or innovative values (Wenger,
1998). There appears to be an ongoing conflict between recruiting new members and developing established members. As indicated in the results, the community is dependent on recruitment to ensure continuance. Still, established members must be able to pursue learning and development in order to carry out their responsibilities within the internal practices. When newcomers develop their identities, there is no guarantee that they maintain or renew the practices (Wenger, 1998). Based on the mutual engagement and generational encounters, various relationships among participants may occur, including confidentiality, competition, challenges and conflicts. Conflicts may appear as a productive part of the community, because the disturbances may cause dynamism within the community and hereby prevent the practices from becoming static and conservative (Wenger, 1998).

Established members are aware of what it takes to contribute to a team at elite level. Based on this knowledge, established members might treat rookies in certain ways while, at the same time, evaluating their potential to claim a suitable informal role and hereby increase the probability to advance towards central positions. However, rookies rarely perceive it this way and often feel like they do not belong to the community. Still, in order to ensure that the shared repertoire and joint enterprise is integrated to rookies' performance of practices, it appears to be worth the risk. For established members it seems important to be aware of and master the balance between friendly bullying and hazing. The reason for this, as it emerges in the results, is that the purpose of the rookie treatment is to promote learning, inclusion, and integration within the community. To accomplish that, a rookie must receive an opportunity to understand and execute the shared repertoire without being exposed to hazing. This allows him to relate to the joint enterprise and participate in it. The results suggest that generational encounters prevent internal practices from becoming static and narrowed, while at the same time 
transferring fundamental values between generations.

Lave and Wenger (2003) argue that learning is not about acquiring a structure. However, participants, who seek learning, are awarded through gradually increased access to experienced practices. In the present context, this occurs through the process of internal advancement. From an individual perspective, all participants, who enter the community, are unique. This uniqueness will result in both similarities and differences among members via their participation and interaction with other members. To maintain heterogeneity and informal roles within the community seems to be of a great importance. Heterogeneity is the foundation for establishing informal roles, which makes the internal practices work. As stated by Wenger (1998), participants will establish their own place, which will serve as a basis for identity construction. In this study, this happens via acquiring and developing formal and informal roles. As learning takes place, participants' identities (such as being a sledge hockey player) become deeper integrated within the team. Despite being interlocked and articulated to each other through the mutual engagement, Wenger (1998) highlights the fact that these identities will, to a certain degree, fuse. In other words, as stated by Logan, every informal role has something of the others within itself.

However, it appears that a certain amount of homogeneity is necessary in order to maintain the fundamental values of the community. Still, the community depends on heterogeneity within the informal roles so that things do not become "all crazy" as stated by Kyle. Informal roles that appeared in this study raise the question, of how narrow these identities appear in practice. Will potential members choose to be or become excluded from the community because of their perception of own participation? Established members are likely to experience a natural promotion and are hereby given increased responsibilities. This might encourage them to establish new identities on the basis of their internal advancement (Wenger, 1998). That happened in this case thanks to the formal roles (e.g. being involved in The Captains Group or a trustee). Development of identity through participation is understood as a continuous social process (Nielsen \& Kvale, 1999).

As stated by Ronglan (2009), it is vital for newcomers to participate in and master the shared repertoire in order to take part in the joint enterprise and begin their journey to central participation. In this context, the demonstration of a shared repertoire appears through acquiring and executing valued attitudes and actions in relation to training, teammates, coaching staff, local jargon and internal practices of the community. There are also other aspects that may influence the internal advancement such as time of service, generational discontinuities and personal development. By participating over time, the members are likely to increase their amount of learning and hereby increase legitimacy. This might affect their personal status and identity. As this development takes place, participants gradually move toward a central position within the community until they obtain the status of full members.

Moreover, after claiming a suitable informal role, it seems as if on-ice learning and development became gradually more important. As stated by Tim, in order to claim formal roles within the team, members must be perceived as strong contributors both on-ice and off-ice. Furthermore, when a central member retires, the room that is left must be refilled. This example of internal advancement might cause ripple effects through all levels of participation. Since the community is characterized by rather frequent replacements, possibilities for internal advancement are likely to occur on a regular basis. That is an important aspect in relation to identity development occurring as a result of generational discontinuities. 


\section{PERSPECTIVE}

The goal of the study was to understand the internal practices of the Norwegian Sledge Hockey Team. To our knowledge, there is limited research driven knowledge concerning coaching and learning in elite sports for people with disabilities (DePauw \& Gavron, 2005). Thus, this study adds to the literature by examining and understanding the learning processes that take place when newcomers enter a Paralympic team sport, in this case the Norwegian Sledge Hockey Team. As the results indicate, it is not necessarily an inclusive world inside the context of disability sports. This being said, if established members, coaching staff and other practitioners become aware of rookies' possible behaviors and reactions that may occur as a result of the internal practices, they might be able to identify and respond to misconducts in an appropriate way that consequently increases learning, inclusion and integration. Another consequence might be that all participants become able to pursue individual and collective learning - both on-ice and off-ice. It is important to highlight that this does not necessarily include a need for changes to internal practices. However, it could be a contributing factor in order to improve the initiation, possibilities for learning and process of internal advancement. In sum, if newcomers experience sufficient legitimacy in accordance with appropriate responses on misconducts from established members, the community's potential for learning will likely be refined and become available to members who may otherwise withdraw from the community.

\section{REFERENCES}

Bakke, R.K., \& Tønnesen, E.S. (2007). Lave \& Wenger og Dreyfus \& Dreyfus - loering $i$ et sosiokulturelt perspektiv.

Hovedfagsoppgave Universitet i Oslo, Det utdanningsvitenskapelige fakultet, Pedagogisk forskningsinstitutt.

Bloom, B. (1985). Developing talent in young people. New York, NY: Ballantine.
Brantlinger, E., Jimenez, R., Klinger, J., Pugach, M., \& Richardson, V. (2005). Qualitative studies in special education. Exceptional Children, 71, 195-207.

Bruner, W.M., Munroe-Chandler, J.K., \& Spink, K.S. (2008) Entry into Elite Sport: A Preliminary Investigation into the Transition Experiences of Rookie Athletes. London: Routledge

Denzin, N. K., \& Lincoln, Y. S. (1994). Handbook of Qualitative Research. London, CA: DePauw, K.P., \& Gavron, S.J. (2005). Disability and sport (2nd ed.). Champaign, IL: Human Kinetics Sage

Guba, E. (1978). Toward a methodology of naturalistic inquiry in educational evaluation. Menograph 8. In: Lincoln, Y. \& Guba, E. (1985). Naturalistic Inquiry. Sage Publications, Newbury Park, California.

Hanks, W.F. (1991) Foreword. In: Lave, J., \& Wenger, E. (1991). Situated Learning: Legitimate Peripheral Participation. Cambridge, UK: Cambridge University Press.

Jespersen, E. (1999). Idrettens kroppslige mesterlære.In K.Nielsen \& S. Kvale (Eds.), Mesterlare. Laring som sosial praksis (pp. 137-148). Oslo: Gyldendal.

Kvale, S., \& Brinkmann, S. (2009). Det kvalitative forskningsintervju. Oslo, Gyldendal Norsk Forlag AS

Lave, J. \& Wenger, E. (1991). Situated Learning: Legitimate Peripheral Participation. Cambridge, UK: Cambridge University Press.

Lave, J., \& Wenger, E. (2003). Situert loering og andre tekster. Hans Reitzels Forlag A/S, København

Lincoln, Y., \& Guba, E. (1985) Naturalistic Inquiry. Sage Publications, Newbury Park, California

Marshall, C., \& Rossman, G. B. (1999). Designing Qualitative Research. Sage Publications London.

Nielsen, K., \& Kvale, S. (1999) Mesterlaerelcering som sosial praksis. Ad Notam Gyldendal

O'Hara, J. (2000). The hell of hazing. At universities and in junior hockey, rookies often undergo barbaric initiation rites. In: W.M. Bruner, J.K. Munroe-Chandler \& S.K. Spink (2008) Entry into Elite Sport: A Preliminary Investigation into the 
Transition Experiences of Rookie Athletes. Routledge

Patton, M. Q. (2002). Qualitative Research \& Evaluation Methods. California, Sage Publications Ltd, London.

Robinson, L. (1998). Baptized a hawk: Initiations in junior hockey. In: W.M. Bruner, J.K. Munroe-Chandler \& S.K. Spink (2008) Entry into Elite Sport: A Preliminary Investigation into the Transition Experiences of Rookie Athletes. Routledge

Ronglan, L.T. (2009). Situert læring - om laget som praksisfellesskap. In: L.T. Ronglan, A. Halling \& G.Teng (red.) Ballspill over grenser - skandinaviske tilnoerminger til loring og utvikling. Akilles, Oslo.

Standal, Ø. F., \& Jespersen, E. (2008). Peers as Resources for Learning: A Situated Learning Approach to Adapted Physical Activity in Rehabilitation, Human Kinetics, Inc.
Thomas, N., \& Smith, A. (2009) Disability, Sport and Society - an introduction. Routledge

Wenger, E. (1998). Communities of Practice. Learning, meaning and identity. Cambridge, UK: Cambridge University Press.

Wenger, E., McDermott, R., Snyder, W.M. (2002). Cultivating communities of practice: A guide to managing practice. Boston: Harvard Business School Press.

\section{AUTHORS NOTE}

Espen Hegde, Department of physical education, Norwegian School of Sport Sciences; Øyvind F. Standal, Department of physical education, Norwegian School of Sport Sciences

Correspondence concerning this article should be addressed to Espen Hegde, Sinsenveien 61b 0586 Oslo, Norway. E-mail: espen_hegde@hotmail.com 